\title{
PANDEMIA E A TECNOLOGIA COMO FERRAMENTA DE ENSINO
}

\section{PANDEMICS AND TECHNOLOGY AS A TEACHING TOOL}

\begin{abstract}
Artur Romão Rocha iD
Bacharel em Ciências Contábeis pela Universidade do Norte do Paraná UNOPAR. Docente na Faculdade de Educação e Meio Ambiente - FAEMA, Ariquemes/RO.

E-mail: arturromaorocha@gmail.com.
\end{abstract}

Dulcilene Nunes Romão iD

Especialista em Metodologia do Ensino de Ciências pela Faculdade Internacional de Curitiba - FACINTER. Docente da Rede Pública de Ensino, Ariquemes/RO.

E-mail: dulce_romao@hotmail.com.

\section{Edgar Nunes Romão}

Especialista em Docência Universitária pelo Centro Universitário Luterano de JiParaná - CEULJI-ULBRA; Especialista em Gestão Escolar Pela Universidade Federal de Rondônia - UNIR. Docente da Rede Pública de Ensino, Ariquemes/RO.

E-mail: edgarnromao.letter@gmail.com.

Submetido: 20 nov. 2021.

Aprovado: 9 dez. 2021.

Publicado: 15 dez. 2021.

\section{E-mail para correspondência:}

arturromaorocha@gmail.com

Este é um trabalho de acesso aberto e distribuído sob os Termos da Creative Commons Attribution License. A licença permite o uso, a distribuição e a reprodução irrestrita, em qualquer meio, desde que creditado as fontes originais.

Imagem: StockPhotos (Todos os direitos reservados).

\section{Open Access}

Resumo: A pandemia da COVID-19 impôs um novo ritmo para a vida das pessoas e na área da educação não foi diferente. Nesse contexto de mudanças significativas, a escola teve que se reinventar, inovar sua prática pedagógica para atender os estudantes em período de afastamento social. O presente artigo com o tema "A pandemia e a tecnologia como ferramenta de ensino" e tem como objetivo abordar as possibilidades de atividades educacionais utilizando as Tecnologias Digitais da Informação e Comunicação, ferramentas disponíveis no mundo virtual. 0 trabalho oportuniza ainda uma abordagem sobre o papel da escola a democratização do ensino e os desafios que professores e estudantes enfrentam nesse momento de adaptação frente a falta de condições ao acesso às tecnologias, dentre outras questões que impactaram a vida da comunidade escolar. Os procedimentos metodológicos estão embasados no levantamento de informações através de pesquisas bibliográficas em publicações online como revistas, legislação e outros na área da saúde e educação.

\section{Palavras-chave: Pandemia. Tecnologias Digitais. Escola.}

Abstract: The COVID-19 pandemic imposed a new rhythm on people's lives and in the area of education it was no different. In this context of significant changes, the school had to reinvent itself, innovate its pedagogical practice to assist students in a period of social withdrawal. This article with the theme "The pandemic and technology as a teaching tool" and aims to address the possibilities of educational activities using Digital Technologies of Information and Communication, tools available in the virtual world. The work also provides an opportunity to approach the role of the school in the democratization of teaching and the challenges that teachers and students face at this time of adaptation in view of the lack of conditions to access technologies, among other issues that impacted the life of the school community. The methodological procedures are based on gathering information through bibliographic research in online publications such as journals, legislation and others in the area of health and education.

Keywords: Pandemic. Digital Technologies. School. 


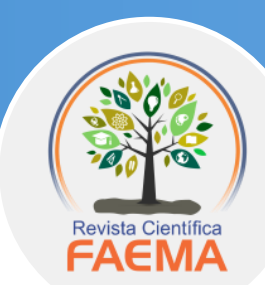

\section{Introdução}

A sociedade no mundo todo, partir de março de 2020, foi surpreendida pela pandemia do COVID-19, um novo agente viral conhecido como corona vírus, descoberto no final de 2019, milhões de pessoas apresentam um quadro clínico que varia de infecções assintomáticas a quadros respiratórios graves que podem levar a morte. Nesse sentido, A Organização Mundial da Saúde (OMS) juntamente com o Ministério da Saúde recomendou como medida de prevenção, o distanciamento social (1).

Com as medidas de distanciamento, segundo Corrêa e Brandemberg (2), a Organização das Nações Unidas para Educação, Ciência e Cultura (UNESCO) estima que mais de um bilhão de discentes estão longe da escola em todo o mundo em decorrência da pandemia. No Brasil, devido ao aumento de casos, as atividades escolares presenciais em todos os níveis foram suspensas pelo Ministério da Educação (MEC), levando aproximadamente quase 53 milhões de discentes a ficarem sem aula ${ }^{(2)}$.

$\mathrm{O}$ surgimento da pandemia alterou os rumos da sociedade no mundo. Na área educacional milhares de estudantes ficaram impedidos de ir à escola, adotando assim isolamento social como medida de prevenção à pandemia. Dessa forma, professores e alunos tiveram que se adaptar às aulas a distância e utilizar toda a criatividade através de diversos recursos tecnológicos disponíveis para dar continuidade as atividades escolares ${ }^{(2)}$.

Assim, sem o retorno presencial das aulas, uma das alternativas encontradas por diversos países, incluindo o Brasil foi a migração das aulas do modelo presencial para o modelo remoto, a transferência das aulas para plataformas online e a utilização das Tecnologias da Informação e Comunicação (TIC) e Tecnologias Digitais (TD), ambas comumente utilizadas na Educação à Distância (2). 


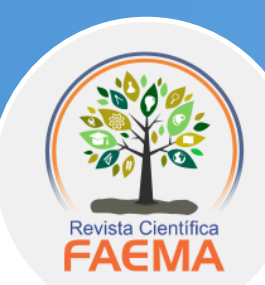

No contexto brasileiro, a implementação da transição do ensino presencial para o ensino remoto, professores e alunos enfrentam grandes desafios como a falta de acesso as tecnologias, os dispositivos mais atuais como o computador, o tablet, o smartphone e qualquer outro dispositivo que permita a navegação na internet (2).

Outra problemática se refere ao fato de que:

[...] boa parte dos professores brasileiros não se encontra, efetivamente, capacitada para desenvolver atividades que integram as tecnologias digitais ao processo de ensino e aprendizagem, seja por não estar inclusa no currículo das disciplinas estudadas na graduação, seja por falta de investimentos ou mesmo incentivos na formação continuada nas políticas educacionais (CORRÊA; BRANDEMBERG, 2021, p.39) ${ }^{(2)}$.

Nesse contexto, a escola atualmente enfrenta novos desafios que é transformar as ferramentas digitais por meio de troca de experiências, discussões e adequações de propostas em instrumentos favoráveis ao desenvolvendo do senso crítico, de habilidades e competências essenciais dos estudantes. Assim entende-se que o uso de tecnologias no ensino passa pela necessidade de formação contínua do professor, promovendo trocas de experiências e fortalecimento do conhecimento (2).

\section{O impacto da pandemia na educação}

Em janeiro de 2020, a Organização Mundial de Saúde (OMS) declarou a COVID19 como uma Emergência de Saúde Pública de Importância Internacional (1). Em 11 de março de 2020, a Covid-19 foi caracterizada como uma pandemia com facilidade de contágio e rápida letalidade, especialmente em idosos. A pandemia instalou-se em poucas semanas nos vários continentes do planeta, assustando profissionais de saúde e toda a população em geral (2).

A partir de março de 2020, de acordo com a UNESCO (3), o mundo se viu diante de uma grande turbulência, mais de 1.5 bilhões de crianças, adolescentes e universitários de diversos países do mundo ficaram afastados da sala de aula. 


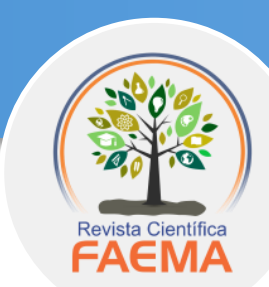

Um grande contingente de países não tinha planos de abertura das escolas devido ao grande avanço da pandemia da COVID-19 (3). O termo isolamento social, pode ser definido como o ato de separar um indivíduo ou um grupo, do convívio com o restante da sociedade. Esse isolamento pode ser voluntário ou forçado (1). 0 Isolamento social que iniciou em março de 2020 no mundo, devido a Pandemia, foi forçado, involuntário, por conta de uma emergência em saúde, como medida urgente de prevenção contra o COVID-19 (3).

Assim, diante da pandemia que afetava o mundo, “[...] as aulas [...] foram suspensas, de início acreditou-se que o retorno seria breve, porém para surpresa dos cidadãos, a medida de prevenção da doença COVID-19 [...] estende-se até os dias de hoje" (SOUZA; ALMEIDA; LUQUETTI, 2020, p. 1329) ${ }^{(4)}$.

Nesse contexto de agravamento do avanço da pandemia, pode-se ressaltar que:

\begin{abstract}
A pandemia afeta a saúde pública de forma agressiva, tirando a vida não apenas dos idosos, considerados inicialmente como o principal grupo de risco, mas crianças, jovens e adultos, também têm sido afetados pela doença. As medidas de isolamento e distanciamento social adotadas por todos os países, por meio do confinamento com regras nem sempre rígidas, para manter a população em casa, tencionam a economia dos países, refletindo na paralisação de distintos serviços e atividades, dentre eles o processo de ensino-aprendizagem (ALVES, 2020, p. 350) ${ }^{(5)}$.
\end{abstract}

Diante da pandemia que se alastrava e com muitas mortes, considerando o Parecer emitido pelo Conselho Nacional de Educação (CNE), no dia 28 de abril de 2020, foram suspensas as aulas presencias como medida de prevenção contra o avanço da doença em todos os níveis de ensino da Educação Infantil até o Ensino Superior, durante a pandemia da COVID-19 (1).

A partir do avanço da pandemia, governos municipais e estaduais estabeleceram medidas de emergência de saúde pública “[...] todos os setores de indústria, economia e educação suspenderam as suas atividades. O Ministério da Educação, através da Portaria $n^{\circ}$ 544/2020, autorizou a substituição das aulas presenciais por meios digitais [...]" (GALINDO et al, 2020, p. 269) ${ }^{(6)}$. 


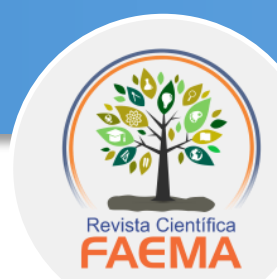

Nesse contexto de grandes mudanças, pode-se apontar que:

[...] Mas, e a escola? Quais os impactos da pandemia na educação? E os professores e professoras, que, como quaisquer outros cidadãos, passam por todas estas dificuldades, como estão vivenciando esta nova realidade? Quais os impactos e desafios da quarentena para escolas, estudantes e professores? Estas questões nos instigam a continuar pesquisando e vivenciando a educação em tempos de pandemia (SOUZA, 2020, p.111) ${ }^{(7)}$.

Entretanto, segundo Souza (7), apesar das TIC já fazerem parte, direta ou indiretamente da rotina das escolas e da realidade de muitos professores e estudantes, a utilização delas no período de pandemia, para substituir os encontros presenciais, tem encontrado vários desafios, como a infraestrutura das casas de professores e estudantes; as tecnologias utilizadas; o acesso ou falta dos estudantes à internet; a formação dos professores para planejar e executar atividades online ${ }^{(7)}$.

Nesse contexto de grandes mudanças, observa-se que as famílias também tiveram que se adaptar à nova realidade, além de cuidar da casa, trabalho, precisaram acompanhar e auxiliar nas atividades encaminhadas pelos professores. Dessa forma, muitos pais enfrentaram dificuldades para acompanhar os filhos nas atividades escolares, pois muitos não tem experiência em ensinar (7).

Para Souza, Almeida e Luquetti (4), de acordo com a Ministério da Saúde ${ }^{(8)}$, através da Portaria $n^{\circ} 356$ de 11 de março de 2020 que regulamenta o disposto na Lei $\mathrm{n}^{\circ} 13.979$ de 6 de fevereiro de 2020, o isolamento social tornou um meio essencial para o combate à doença, como cuidados de higiene, medidas preventivas. Nesse contexto, as aulas no território e nesse contexto de mudanças surgiram muitos desafios no cenário educacional, novas estratégias na prática pedagógica vêm se reinventando ao longo do período ${ }^{(4,8)}$.

Nesse processo de mudanças, observa-se que o isolamento social foi necessário como medida de prevenção da doença, entretanto, trouxe inúmeros prejuízos ao ser humano, surgimento de problemas psicológicos como ansiedade e depressão, crise financeira, índice de desemprego que afetou de forma significativa as famílias brasileiras, aumentando o número de pobreza extrema no país ${ }^{(4,7)}$. 


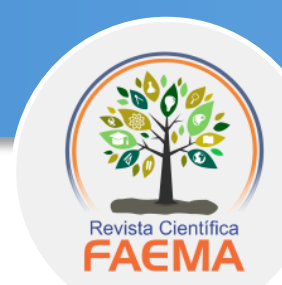

\section{As tecnologias adotadas para mediação pedagógica}

Ao tratar de uma alternativa pedagógica rápida para atender os alunos durante a pandemia com o distanciamento social, de acordo com Santana e Sales (2020), buscou-se como soluções a partir da realidade que se vive, atividades em casa foi uma adaptação por grande parte das Instituições Educacionais do país para estudantes das redes públicas durante a pandemia de COVID-19.

Dessa forma, segundo Santana e Sales ${ }^{(9)}$, a Lei de Diretrizes e Bases (LDB) $n^{\circ}$ 9394/96, a Educação a Distância (EaD) adquiriu uma centralidade nas demandas e preocupações da sociedade brasileira a partir do distanciamento social imposto pela Pandemia de COVID-19. As instituições de ensino, os órgãos gestores, os conselhos de regulação, a mídia e a sociedade passaram a falar de EaD como alternativa para o momento ${ }^{(9)}$.

Ao tratar da Educação a Distância (EaD), segundo a atual legislação nacional, ressalta-se que:

[...] na Lei de Diretrizes e Bases da Educação Nacional (LDB) em nenhum momento aborda o termo ensino remoto, apenas menciona a Educação à Distância como modalidade de ensino, a qual é regulamentada pelo Ministério da Educação (MEC), que a caracteriza como modalidade de ensino em que todos os envolvidos se encontram separados fisicamente e temporalmente e, desse modo, utilizam a tecnologia para criar esse processo de aprendizagem. Assim, o ensino remoto apenas se assemelha a EAD no contexto do uso das tecnologias, mas os princípios que o embasam são do ensino presencial (CORRÊA; BRANDEMBERG, 2021, p. 37) ${ }^{(9)}$.

Com a emergência da pandemia, segundo Santana e Sales (9), as escolas precisaram se organizar para migrar para o ensino com o uso das tecnologias digitais. Esta migração gerou uma transposição de práticas e metodologias do ensino presencial para as plataformas virtuais de aprendizagem, o chamado ensino remoto. No ensino remoto, transferiu o que já se fazia na sala de aula presencial e, em muitos casos, aflorou uma perspectiva de educação instrucionista e conteudista ${ }^{(9)}$. 


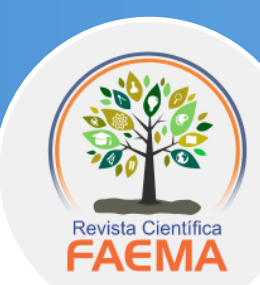

Sobre a necessidade do ensino remoto diante do distanciamento social como medida de prevenção contra a pandemia, destaca-se que:

O distanciamento físico social transpôs a educação para contextos remotos sem considerar fundamentos pedagógicos da literatura e pesquisas em $\mathrm{EaD}$ ou Educação Online. Assim, essas práticas, além de se apresentarem pouco efetivas no que diz respeito à qualidade do processo formativo, podem comprometer o percurso de construção de uma cultura institucional para o desenvolvimento dos processos formativos na modalidade a distância (SANTANA; SALES, 2020, p.75) ${ }^{(9)}$.

Para Corrêa e Brandemberg (2), a utilização do termo Tecnologias da Informação e Comunicação (TIC) se refere aos dispositivos eletrônicos e tecnológicos mais antigos, em que se incluem o rádio, a televisão, o jornal, mimeógrafo, e até as mais atuais como o computador, a internet, o tablet e smartphone os quais tem a finalidade de informar e comunicar. Atualmente, usa-se o termo Tecnologias Digitais da Informação e Comunicação (TDIC) para designar os dispositivos mais atuais como o computador, o tablet, o smartphone e qualquer outro dispositivo que permita a navegação na internet ${ }^{(2)}$.

Nesse sentido, pode-se afirmar que:

[...] as TDIC são compreendidas como um conjunto de equipamentos e aplicações tecnológicas que geralmente utilizam a internet e diferenciam-se das Tecnologias de Informação e Comunicação (TIC) também pela presença do termo digital" (CORRÊA; BRANDEMBERG, 2021, p.38) ${ }^{(2)}$.

Entre as várias ferramentas utilizadas, segundo Santana e Sales ${ }^{(9)}$, estudos apontam que os estudantes em medidas de prevenção, em isolamento social contam com atividades orientadas diversificadas. Entre as várias atividades, podemos citar as atividades transmitidas pela TV; uso de aplicativos para o esclarecimento de dúvidas; conteúdos audiovisuais são ainda disponibilizados em canal do YouTube, videoaulas; ou ainda plataforma com material apostilado. 


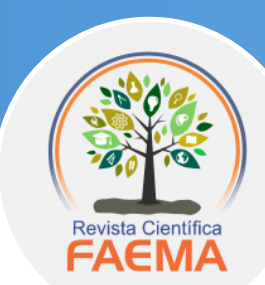

Para a Educação Infantil e o Ensino Fundamental I, os conteúdos audiovisuais têm formato diversificado e lúdico. Outras regiões adotou a ferramenta Google Classroom como espaço pedagógico. Na plataforma ocorrerão aulas on-line pelo Google Meeting, bem como a utilização de todos os recursos pedagógicos disponíveis na referida plataforma. E os estudantes sem acesso à internet podem retirar os materiais impressos na escola ${ }^{(9)}$.

Assim, observa-se as inúmeras ferramentas, meios utilizados para que os estudantes sejam atendidos durante o período pandêmico, vale enfatizar que:

\begin{abstract}
Não se trata [...] de utilizar as tecnologias a qualquer custo, mas sim de acompanhar consciente e deliberadamente uma mudança de civilização que questiona profundamente as formas institucionais, as mentalidades e a cultura dos sistemas educacionais tradicionais e, sobretudo, os papéis de professor e de aluno (LÉVY, 2005, p. 172) ${ }^{(10)}$.
\end{abstract}

A utilização das tecnologias digitais, de acordo com Corrêa e Brandemberg (2), esbarra em alguns entraves como as dificuldades na adaptação que muitos professores enfrentam na utilização dessas tecnologias, e acabam por deixar de fazer uso destes recursos em suas práticas. Vivemos em uma sociedade marcada pelo desenvolvimento tecnológico, logo a educação que possui um papel fundamental não deve estar a margem desse desenvolvimento, e assim o uso de recursos tecnológicos são indispensáveis pelo educador, cabendo a este a busca da apropriação do conhecimento para a utilização em sala de aula e fora dela (2).

\title{
Os desafios da Educação à Distância
}

A educação a distância, conforme Souza ${ }^{(4)}$, representa uma modalidade de ensino que vem sendo utilizada há muito tempo. Inicialmente, utilizava-se a correspondência como tecnologia mediadora entre aluno e professor. 


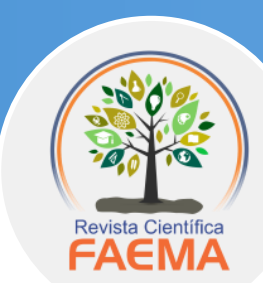

Depois chegaram o rádio e as TVs Educativas, que foram importantes para a educação brasileira nas décadas de 1960 a 1990, auxiliavam na qualificação de muitos trabalhadores. Esse tipo de educação a distância de massa ainda tem reflexos atualmente nos cursos que utilizam tecnologias digitais (4).

Entretanto, apesar dos avanços atuais em diversos setores, principalmente no campo da economia e da tecnologia, de acordo com dados da PNAD (11), é possível afirmar que:

[...] 20,9\% dos domicílios brasileiros não têm acesso à internet, isso significa cerca de 15 milhões de lares. Em 79,1\% das residências que têm acesso à rede, o celular é o equipamento mais utilizado e encontrado em $99,2 \%$ dos domicílios, mas muitas famílias compartilham um único equipamento. Outra realidade que não podemos desconsiderar é que as casas das classes médias e alta têm uma estrutura privilegiada para o desenvolvimento de atividades escolares. Porém, as residências das classes populares se configuram, em geral, com poucos cômodos onde convivem várias pessoas, tornando-se difícil a dedicação dos alunos às atividades escolares. Pesquisa [...] mostra que $11 \%$ das crianças e adolescentes de 9 a 17 anos não têm acesso a internet, correspondendo a 3 milhões de pessoas, sendo que 1,4 milhão nunca acessou a rede. Estes dados enfatizam um dos desafios da educação no período da pandemia, que é o acesso das pessoas à rede internet banda larga para continuarem aprendendo e ensinando (BRASIL, 2018) ${ }^{(11) .}$

Em meios a grandes desafios, os professores confrontaram-se com a dificuldade de acesso, por parte de muitas famílias onde não possuíam uma alternativa a não ser um telefone com o aplicativo de mensagens. Assim, observa-se a importância de recursos como acesso à internet para que os estudantes consigam realizar as atividades propostas. Os professores tiveram que se adaptar à nova realidade e passaram a usar os recursos midiáticos: criação de vídeo aulas para que os alunos tivessem acesso de forma assíncrona e autoinstrucional ao conteúdo (9). De acordo com pesquisa realizada pelo Instituto Península em $2020{ }^{(4)}$, apontaram que:

[...] $88 \%$ dos professores nunca tinham dado aula de forma remota e $83,4 \%$ não se sentem preparados. Observamos que mesmo os professores que já utilizavam as tecnologias digitais como apoio ao ensino presencial encontraram dificuldade para se adaptar ao ensino remoto, visto que muitos não têm infraestrutura adequada em suas casas, tampouco formação específica para atuar na docência online (SOUZA, 2020, p. 113) ${ }^{(4)}$. 


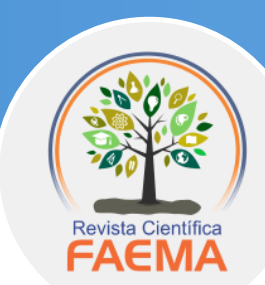

Nesse sentido, observa-se que as iniciativas dos estados resultaram na preocupação em garantir a transmissão de conteúdo no formato equivalente ao que se faz nas salas de aulas presenciais. Reconhece-se, portanto, que os sistemas de ensino, estão desenvolvendo ações pedagógicas de forma experimental. Nesse sentido, a educação precisou acelerar para chegar ao século XXI, buscando alternativas, inovações através de diversas ferramentas virtuais para resolver a questão da relação aluno, professor e escola diante do distanciamento nesse período de pandemia ${ }^{(4)}$.

Para os docentes, a transição para o ensino remoto, segundo Corrêa e Brandemberg (2), representa grandes desafios, uma vez que boa parte dos professores brasileiros não se encontra, efetivamente, capacitada para desenvolver atividades que integram as tecnologias digitais ao processo de ensino e aprendizagem, seja por não estar inclusa no currículo das disciplinas estudadas na graduação, seja por falta de investimentos ou mesmo incentivos na formação continuada nas políticas educacionais. Para que de fato se busque atingir a proposta do uso de tecnologias no ensino, há necessidade de formação contínua do professor, promovendo trocas de experiências e fortalecimento do conhecimento, reforçando que o professor será o mediador do processo de ensino e aprendizagem e os alunos protagonistas se apropriando do conhecimento (2).

Ao tratar da importância da formação de professores para uso das tecnologias digitais, é importante ressaltar que:

A apropriação do conhecimento amplia as possibilidades de atuação, podendo transformar estas ferramentas e/ou objetos de estudos em instrumentos de contribuição recíproca entre professores/alunos por meio de troca de experiências, discussões e adequações de propostas, fomentando assim o senso crítico do aluno, desenvolvendo as habilidades e competências essenciais e almejadas (CORRÊA; BRANDEMBERG, 2021, p. 39) (2). 


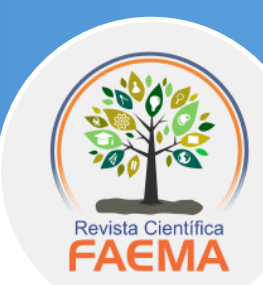

Assim, pode-se afirmar que “[...] a formação de professores é antes uma práxis que uma teoria sobre uma prática. O ensino remoto tornou-se um desafio para esses profissionais que precisaram aprender na prática a usar as TIC para desenvolver as suas aulas (SOUZA, 2020, p. 113) ${ }^{(4)}$.

Entretanto, a escola, a educação enfrentam imensos desafios, é possível se deparar com grandes desigualdades de acesso às tecnologias, temos um contingente enorme de estudantes sem computador ou tablet conectados à internet. Assim, as ferramentas remotas precisam ter parâmetros de qualidade, para que tenham maior eficácia no processo ensino e aprendizagem ${ }^{(4)}$.

No período da pandemia, para Souza ${ }^{(4)}$, novas relações afetivas e profissionais foram criadas e ressignificadas, muitas pessoas passaram a trabalhar remotamente; famílias passaram a conviver cotidianamente com vários conflitos; pessoas ficaram afastadas de entes queridos para se proteger e proteger o outro; muitos continuaram nas suas atividades por serem essenciais, por não terem outra opção para se manter ou mesmo por não acreditarem que o vírus é real. Enfim, é uma nova realidade que se apresenta (4).

\section{Considerações Finais}

Ao analisar a pandemia como grande acontecimento que mudou os rumos da educação e a migração do ensino presencial para o ensino remoto com o uso da tecnologia como ferramenta de ensino, foi possível observar que o grande desafio de um ensino remoto exige dos professores condições de se adaptação dos conteúdos, de novas dinâmicas em sala de aula entre outras atividades (2).

Nesse cenário de mudanças, constatou-se ainda que estudantes e professores necessitam de recursos de internet, bem como certo conhecimento de suas ferramentas de modo a implementar o encaminhamento das atividades educacionais (9). 


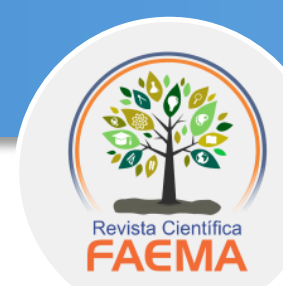

Entretanto, estudos apontam que o ensino remoto não representa a democratização do ensino nas escolas públicas brasileiras, tendo em vista que uma parcela significativa de estudantes no Brasil não tem acesso à internet o que dificultou o uso de plataformas e outros meios ${ }^{(4)}$.

A grande maioria das famílias brasileiras residem em péssimas condições de moradia, sem alimentação, trabalho, saúde e educação. E nesse contexto, uma parcela significativa de estudantes enfrenta dificuldades de aprendizagem e necessita do acompanhamento e intervenção dos professores e família.

As tecnologias digitais atualmente representam um avanço significativo na sociedade globalizada, no entanto, os professores enfrentam dificuldades em fazer uso dessas ferramentas no que se refere ao tempo, espaço e diferentes contextos de aprendizagem ${ }^{(5)}$.

Dessa forma, observa-se que sem políticas públicas de melhoria de acesso as tecnologias, materiais e infraestrutura das escolas, a educação não avança e fracassa de forma significativa afetando milhões de estudantes. Nesse sentido, é urgente e necessário a implementação de políticas públicas comprometidas com o investimento de materiais e equipamentos que possam promover de forma significativa o aperfeiçoamento dos professores atendendo suas reais necessidades de atuação na prática pedagógica ${ }^{(6)}$.

\section{Referências}

1 Brasil. Ministério da Saúde. Sobre a doença: o que é COVID-19. Brasília: MS; 2020. [citado em 12 mar. 2021]. Disponível em: https://bit.ly/2SrBREc.

2 Corrêa JNP, Brandemberg JC. Tecnologias Digitais da Informação e Comunicação no Ensino de Matemática em Tempos de Pandemia: desafios e possibilidades. Boletim Cearense de Educação e História da Matemática. 2021;8(22):34-54. 


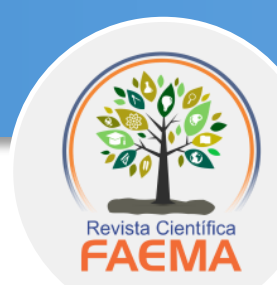

3 Organização das Nações Unidas para Educação, Ciência e Cultura (UNESCO). A UNESCO reúne organizações internacionais, sociedade civil e parceiros do setor privado em uma ampla coalizão para garantir a Aprendizagem Nunca Para. 26 mar. 2020 [citado em 5 maio 2021]. Disponível em: https://pt.unesco.org/news/unescoreune-organizacoes-internacionais-sociedade-civil-e-parceiros-do-setor-privado-emuma.

4 Souza KCCL, Almeida LS, Luquetti ECF. De repente, professor digital: percepções de professores alfabetizadores sobre o ensino remoto. Revista Philologus. 2020;26(78).

5 Alves L. Educação remota: entre a ilusão e a realidade. Educação. 2020;8(3):348365.

6 Galindo AFL, Parente RTX, Diógenes LAS. Os efeitos da pandemia no processo da alfabetização das crianças: elementos de contextualização a partir da perspectiva docente. Revista eletrônica Arma da Crítica. 2020;(14).

7 Souza EP. Educação em tempos de pandemia: desafios e possibilidades. Cadernos de Ciências Sociais Aplicadas. 2020;17(30).

8 Brasil. Ministério da Saúde. Portaria $n^{\circ}$ 356, de 11 de março de 2020. Dispõe sobre a regulamentação e operacionalização do disposto na Lei $n^{\circ} 13.979$ que estabelece as medidas para enfrentamento da emergência de saúde pública de importância internacional decorrente da corona vírus (COVID-19). Brasília: MS; 2020.

9 Santana CLS, Sales KMB. Aula em Casa: educação, tecnologias digitais e pandemia Covid-19. Interfaces Científicas. 2020;10(1):75-92.

10 Levy P. Cibercultura. São Paulo: Editora; 2008.

11 Brasil. Instituto Brasileiro de Geografia e Estatística (IBGE). Pesquisa Nacional por Amostra de Domicílios Contínua - PNAD Contínua 2018. Rio de Janeiro: IBGE, 2018 [citado em 25 nov. 2021]. Disponível em:https://biblioteca.ibge.gov.br/visualizacao/livros/liv101705_informativo.pdf. 